\title{
Structural Design for a Neptune Aerocapture Mission
}

\author{
R. Eric Dyke* \\ Swales Aerospace, NASA Langley Research Center, Hampton, VA 23681 \\ Glenn A. Hrinda $†$ \\ NASA Langley Research Center, Hampton, VA 23681
}

\begin{abstract}
A multi-center study was conducted in 2003 to assess the feasibility of and technology requirements for using aerocapture to insert a scientific platform into orbit around Neptune. The aerocapture technique offers a potential method of greatly reducing orbiter mass and thus total spacecraft launch mass by minimizing the required propulsion system mass. This study involved the collaborative efforts of personnel from Langley Research Center (LaRC), Johnson Space Flight Center (JSFC), Marshall Space Flight Center (MSFC), Ames Research Center (ARC), and the Jet Propulsion Laboratory (JPL). One aspect of this effort was the structural design of the full spacecraft configuration, including the ellipsled aerocapture orbiter and the in-space solar electric propulsion (SEP) module/cruise stage. This paper will discuss the functional and structural requirements for each of these components, some of the design trades leading to the final configuration, the loading environments, and the analysis methods used to ensure structural integrity. It will also highlight the design and structural challenges faced while trying to integrate all the mission requirements. Component sizes, materials, construction methods and analytical results, including masses and natural frequencies, will be presented, showing the feasibility of the resulting design for use in a Neptune aerocapture mission. Lastly, results of a post-study structural mass optimization effort on the ellipsled will be discussed, showing potential mass savings and their influence on structural strength and stiffness
\end{abstract}

\section{Nomenclature}

$\begin{array}{ll}A l & =\text { aluminum } \\ A R C & =\text { Ames Research Center } \\ A U & =\text { astronomical units } \\ B / S & =\text { backshell } \\ C B E & =\text { current best estimate } \\ C G & =\text { center of gravity } \\ F / B & =\text { forebody } \\ F E A & =\text { finite element analysis } \\ F E M & =\text { finite element model } \\ F S & =\text { factor of safety } \\ G r & =\text { graphite } \\ H G A & =\text { high gain antenna } \\ J P L & =\text { Jet Propulsion Laboratory } \\ J S F C & =\text { Johnson Space Flight Center } \\ L a R C & =\text { Langley Research Center } \\ L / D & =\text { lift/drag }\end{array}$

*Structural Engineer, Swales

Aerospace/Vehicle Analysis Branch, MS360

$\dagger$ Structural Engineer, Vehicle Analysis

Branch, Aerospace Systems Concepts and

Analysis Competency, MS353X 


$\begin{array}{ll}M A C & =\text { mass acceleration curve } \\ M E L & =\text { master equipment list } \\ M S & =\text { margin of safety } \\ M S F C & =\text { Marshall Space Flight Center } \\ N S M & =\text { non-structural mass } \\ O M L & =\text { outer mold line } \\ P A F & =\text { payload adapter fitting } \\ P M & =\text { propulsion module } \\ S A & =\text { solar array } \\ S E P & =\text { solar electric propulsion } \\ T P S & =\text { thermal protection system } \\ X e & =\text { Xenon }\end{array}$

\section{Introduction}

Q tructural sizing for a conceptual aerocapture spacecraft to Neptune was required to establish concept feasibility Sand to obtain preliminary component mass estimates. The full spacecraft launch stackup consisted of an ellipsled aerocapture/orbiter vehicle sitting atop a propulsion module (PM)/cruise stage, all designed to fit within the 5 meter fairing of a Delta IV Heavy launch vehicle ${ }^{1}$. The PM/cruise stage contained the solar arrays (SA's), Xenon (Xe) tank and other subsystems for the $30 \mathrm{~kW}$, 6-engine solar electric propulsion (SEP) system to be used out to 3 AU. It also held a small hydrazine fuel tank, telecommunication antennae, navigation equipment, thermal radiators, and two Neptune direct entry atmospheric probes which were considered simple lumped masses for this study.

There were four basic objectives for the structural analysis: 1) Support all science payload and subsystem components in the required volume, 2) Meet minimum stackup natural frequencies at launch, 3) Sustain structural stresses at launch and during aerocapture with acceptable margins of safety (MS), and 4) meet the above three objectives with minimal structural mass. Objective 1) above was accomplished by multiple packaging/analysis iterations between JPL and LaRC personnel, producing several ellipsled orbiter configurations and overall size changes before an acceptable design was found. Launch loading criteria from the Boeing Payload Planners Guide ${ }^{2}$ and aerocapture loading criteria from NASA Langley Monte Carlo simulations ${ }^{3}$ were used in conjunction with the commercially available finite element analysis (FEA) software I-DEAS ${ }^{4}$ to size structure with acceptable strength and stiffness to meet objectives 2) and 3) above. I-DEAS FEA and hand calculations were used to size the ellipsled orbiter and the PM/cruise stage during the scheduled design/analysis cycle. Due to challenges in packaging all of the required payload instruments and subsystem components to meet design functionality and overall center of gravity (CG) requirements, and to the ensuing shortened time available for analysis, mass optimization was performed after the scheduled design/analysis cycle. The commercially available software HyperSizer ${ }^{\mathrm{TM}}{ }^{5}$ was used to help reduce mass on the ellipsled orbiter. No similar mass optimization effort was done on the $\mathrm{PM} /$ cruise stage.

The resulting structure consists of a composite material honeycomb sandwich construction ellipsled orbiter aeroshell surrounding a deep-rib stiffened honeycomb sandwich payload deck. The ellipsled orbiter aeroshell is separate forebody (F/B) and backshell (B/S) pieces integrally stiffened with longitudinal and circumferential blades. The $\mathrm{F} / \mathrm{B}$ and $\mathrm{B} / \mathrm{S}$ separate from the payload deck after aerocapture via several pyrotechnic separation fittings. The resulting $\mathrm{PM} /$ cruise stage is a stiffened $\mathrm{Al}$ skin with $\mathrm{Al}$ rings and trusses to support the hydrazine and $\mathrm{Xe}$ tanks and the two direct entry probes and an $\mathrm{Al}$ frame to support the SEP engines.

\section{Functional Requirements}

\section{A. Orbiter Shape Selection}

Neptune atmosphere profiles developed by Justus, Duvall, and Keller ${ }^{6}$ at MSFC and Neptune atmosphere entry parameters developed by $\mathrm{JPL}^{7}$ and $\mathrm{LaRC}^{3}$ personnel were used to determine the required aerocapture vehicle shape and aerodynamic characteristics to meet the stringent entry corridor needed for aerocapture at Neptune ${ }^{3}$. Edquist ${ }^{8}$ (LaRC) evaluated the aerodynamics of several entry vehicle shape classes, including sphere-cone, biconic, bent biconic, and ellipsled, to find an appropriate shape giving the necessary volume and aerodynamic lift to drag ratio (L/D). The resulting vehicle, as shown in Fig. 1, was an ellipsled shape with a flattened bottom. The general ellipsled shape is a body of revolution with an ellipsoid nose and circular cylinder aft end. The flattened ellipsled has an upper portion that is half a body of revolution and a lower portion that is a general ellipsoid nose and elliptical aft cylinder. 


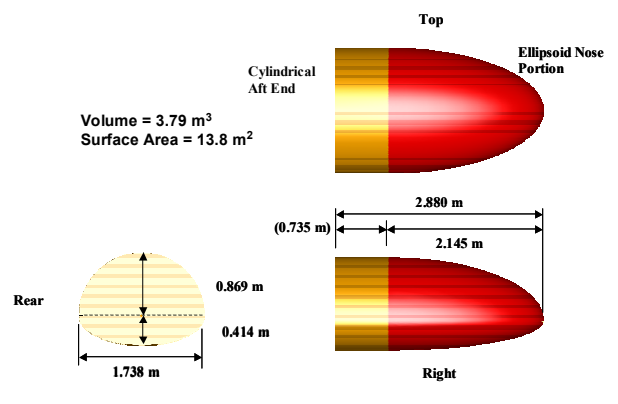

Figure 1. Flattened Ellipsled Geometry

\section{B. Orbiter and PM/Cruise Stage Requirements}

The primary functions of the ellipsled orbiter were to provide the aerodynamic shape necessary to facilitate orbiter aerocapture using the Neptunian atmosphere, to provide the volume necessary to package the scientific payload and other subsystems, to provide sufficient structural MS for natural frequency, buckling, and static stress for launch and aerocapture loading, and to do all of the above with minimal structural mass and complexity. There were several challenges to overcome in fulfilling these functions. The ellipsled aeroshell structure had to support a high thermal protection system (TPS) mass ${ }^{9}$ due to the high aeroheating during aerocapture ${ }^{10}$. The numerous payload and other subsystem components had to be packaged to allow their proper functions but also to provide proper overall mass CG to maintain the required ellipsled angle of attack for aerodynamic control and stability during the full aerocapture phase ${ }^{8,11}$. There were also large variations in aerocapture g loads during the course of the conceptual design phase. These challenges required multiple ellipsled sizing iterations as detailed in a later section.

The primary functions of the PM/cruise stage were to support the ellipsled during launch and cruise; to provide attachments for the two direct entry Neptune probes, telecom antennae, thermal control radiators, and SEP system components; to provide sufficient structural MS for natural frequency, buckling, and static stress for launch loading; and to do all of the above with minimal structural mass and complexity. The primary challenge for the PM/cruise stage structure was providing for the numerous component attachments in a compact design without compromising their proper functions. The two direct entry probes required specific alignment to allow separation independent of each other and the ellipsled and to allow separation along a vector going through (or as close as possible to) the vehicle CG. The large ellipsled mass sitting on top during launch also required extra PM/cruise stage stiffness to meet the stackup launch natural frequency requirements.

\section{Structural Analysis Requirements}

\section{A. Design Loads}

Design launch loads were taken from the Boeing Payload Planners Guide for the Delta IV $\mathrm{Heavy}^{2}$, and are summarized in Table 1 below. For the static analysis and natural frequency calculations, the full stackup was assumed restrained at the payload adapter fitting (PAF). Aerocapture design g loads were taken from the 3-sigma $g$ loads from the Monte Carlo entry analysis ${ }^{3}$, and were balanced with aeropressure loads on the ellipsled aeroshell using an unpublished coarse pressure distribution from N. Takashima (AMA/LaRC) dated September 12, 2003. Component level loads from mass acceleration curves (MAC's), and sine, random, and acoustic loading were not analyzed as part of this study.

Table 1. Static Load Factors

\begin{tabular}{|l|l|}
\hline Event & Loading \\
\hline Launch & 6.0 g's axial $+\mathbf{0 . 5 g}$ 's lateral, any direction \\
\hline & 2.3 g's axial +2.0 g's lateral, any direction \\
\hline Aerocapture & 22.1 g's, acting 11.3 degrees aft of vertical relative to ellipsled payload deck \\
\hline
\end{tabular}




\section{B. Strength and Stiffness}

Standard strength and stability factors of safety (with verification) listed in Table 2 below were used in the structural analysis.

Table 2. Analytical Factors of Safety

\begin{tabular}{|l|l|}
\hline Mode & Factor of Safety \\
\hline Metallic ultimate stress & 1.4 \\
\hline Metallic yield stress & 1.25 \\
\hline Stress in composites & 1.4 \\
\hline Buckling & 1.5 \\
\hline
\end{tabular}

Stackup minimum required natural frequencies at launch, taken from the Boeing Payload Planners Guide for the Delta IV Heavy ${ }^{2}$, were $>8 \mathrm{~Hz}$ for the fundamental lateral modes, and $>30 \mathrm{~Hz}$ for the fundamental axial mode.

\section{Analysis Methods}

Standard "stick and panel" finite element model (FEM) construction with 2-D (non-solid) elements was used for all structural analyses. Components such as the two direct entry probes, radiators, science instruments, fuel tanks/fuel, etc., were modeled as lumped masses and connected to the vehicle structure using rigid-type element connectors or beam elements as appropriate. All FEM's were constructed with I-DEAS, and solved with I-DEAS ( $2.88 \mathrm{~m}$ ellipsled) or NASTRAN (5.5m ellipsled) as described below.

The structural analysis was done in two phases. First, the ellipsled was analyzed using the aerocapture pressure loads with an inertia relief solution method that balances the pressures with entry g loads. The TPS was modeled as non-structural mass (NSM) on the aeroshell elements using areal densities provided by B. Laub (ARC) ${ }^{9}$ with $30 \%$ growth factors applied. For the structural analysis, the F/B TPS areal density $\left(55.4 \mathrm{~kg} / \mathrm{m}^{2}\right)$ and B/S and base TPS areal density $\left(5.54 \mathrm{~kg} / \mathrm{m}^{2}\right)$ were each assumed constant, making two TPS zones. Later TPS analysis modified this to four TPS zones ${ }^{12}$ in an effort to help reduce TPS mass, but was not available in time for this structural analysis. Instruments and other subsystem components were modeled as lumped masses with $30 \%$ growth factors applied. Non-point masses such as thermal blankets, cabling, etc., were added to the payload deck as NSM with 30\% growth factors applied. The ellipsled aeroshell and payload deck structure were then sized and the resulting structure masses were considered current best estimate (CBE).

For the full stackup at launch, the ellipsled structure mass was adjusted to include the $30 \%$ growth factor, with the growth portion being applied as NSM to the existing structure plate elements. The SEP/cruise stage payload components (radiators, probes, fuel tanks, etc.) were modeled as lumped masses with the $30 \%$ growth factors applied. Non-point masses such as cabling, etc., were added as NSM to the cruise stage cylinder and thrust tube. The stackup structure was then sized for the launch loads, and the resulting structure masses for the PM/cruise stage were considered CBE. After the preliminary structure sizing for static loads, the ellipsled was evaluated for buckling under aerocapture loads. The full stackup was evaluated for natural frequency and buckling in the launch configuration under launch loads.

\section{Orbiter Size Iterations}

\section{A. $5.5 \mathrm{~m}$ Ellipsled Design}

The ellipsled aeroshell was initially $5.5 \mathrm{~m}$ long, maximized to fit in a Delta IV Heavy $5 \mathrm{~m}$ fairing ${ }^{2}$. The length was determined by ratioing the maximum aeroshell width that could fit inside the Delta IV fairing. This provided the largest orbiter volume for science payloads and greatest width for mounting a rigid high gain antenna (HGA). Different internal structures to support the rigid aeroshell and mount payloads were tried. Figure 2 shows an early concept using a space truss to maintain the outer mold line (OML) of the aeroshell. 


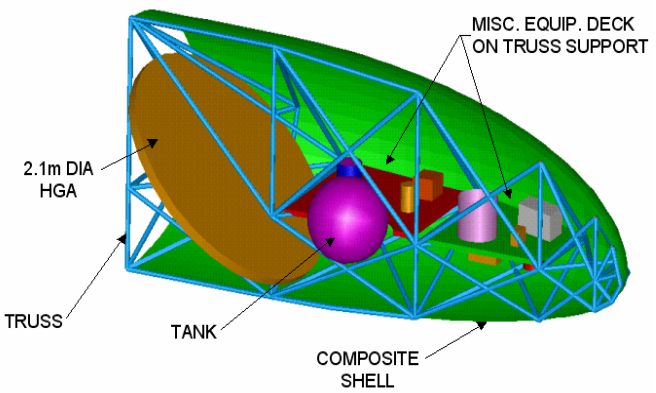

Figure 2. Internal Space Truss

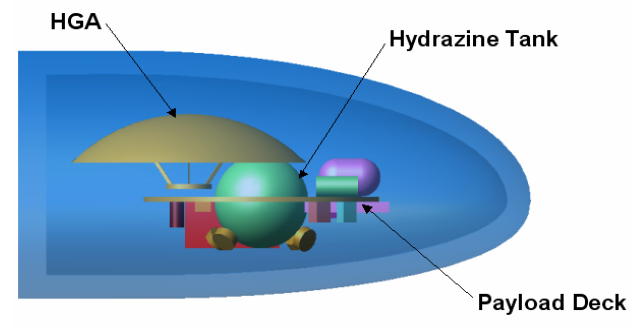

Figure 3. Internal Payload Deck

This configuration relied on the trusses for all equipment mounting and did not require large stiffening of the shell. The load path from all payload and aeroshell mass continued through the space truss into a cruise stage adapter. The purpose of using the space truss was to minimize aeroshell mass with an efficient, highly stiff internal support system. As the design study proceeded, the payload requirements and their configurations inside the ellipsled were constantly being revised. As a result, the internal truss design became difficult to alter while trying to package the rigid HGA within the trusses. A second method was tried that used a flat, stiffened deck for mounting the payload. The flat payload platform offered a convenient surface for securing equipment and also allowed for quick component configuration changes. Figure 3 shows the flat payload deck and major components of the orbiter.

A single hydrazine tank was located near the ellipsled CG with a rigid HGA mounted as shown. The rigid antenna was oriented to fit inside the aeroshell and mounted to the payload deck. The load path for this concept had the aeroshell supporting the payload deck during launch. All loads would then be taken into an elliptic thrust adaptor and continue through to the cruise stage. The cruise stage configuration during this time of the design study was unknown so a cruise stage from an earlier design study ${ }^{13}$ was used. Figure 4 shows the FEM of the ellipsled with its adapter and cruise stage.

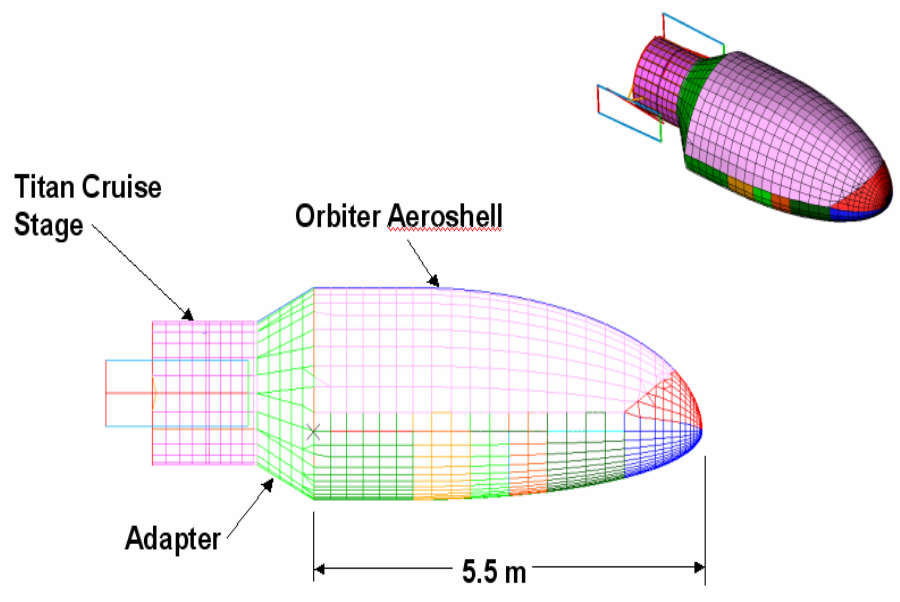

Figure 4. 5.5m Ellipsled with Preliminary Adapter/Cruise Stage

\section{B. 5.5m Ellipsled Structural Analysis}

The $5.5 \mathrm{~m}$ ellipsled aeroshell structure was analyzed using standard FEA combined with a non-deterministic structural sizing program called HyperSizer ${ }^{\mathrm{TM}}$ which allows many trial composite sections and materials to be analyzed very efficiently using only one coarsely meshed FEM. The HyperSizer ${ }^{\mathrm{TM}}$ analysis started with a coarse NASTRAN ${ }^{14}$ FEM of the full stack shown in Fig. 4, subjected to launch loads. That FEM, containing only CQUAD4, CTRIA3, CONM2, and CBAR NASTRAN elements, was solved with NASTRAN and the mesh and resulting element internal loads were imported to HyperSizer ${ }^{\mathrm{TM}}$. Figures 5 and 6 show how the FEM was divided 
into major components reflecting the mission of the orbiter. HyperSizer ${ }^{\mathrm{TM}}$ did not require structure remeshing to reflect structural changes necessary to support changing payload components from the master equipment list (MEL).

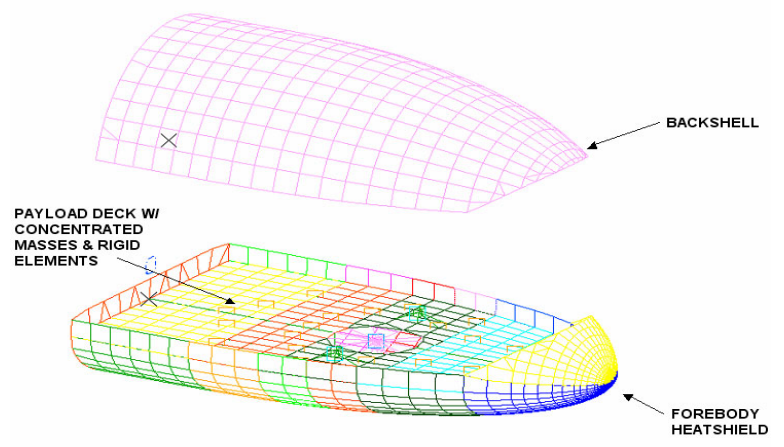

Figure 5. Major Aeroshell Components Figure

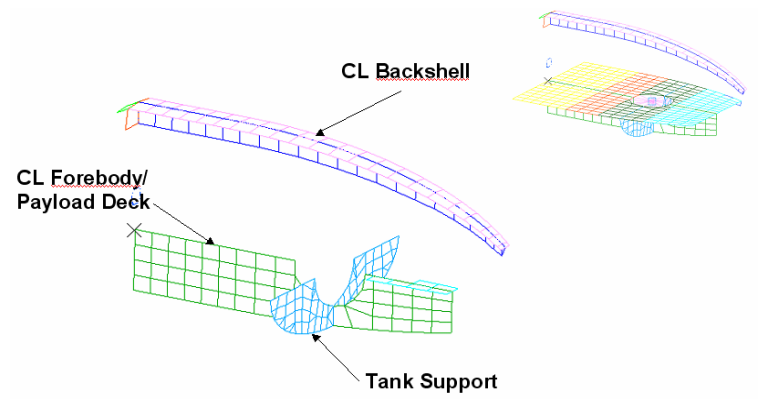

Figure 6. Internal Stiffening Structure

Detailed finite element modeling of panel stiffening methods was not necessary. Within HyperSizer ${ }^{\mathrm{TM}}$, a user can choose among many common aerospace structural concepts such as blade-stiffened panels, honeycomb core panels and isogrids while still using the same coarse FEM. Figure 7 shows the analysis path taken by HyperSizer ${ }^{\mathrm{TM}}$. Each color shown in the figure represents a group of finite elements with common NASTRAN property and material cards, lumped together as a component (or "panel") when imported into HyperSizer" ${ }^{\mathrm{TM}}$. The figure shows the payload deck divided into four components that will each be sized for optimal panel stiffening method, thickness, and material.

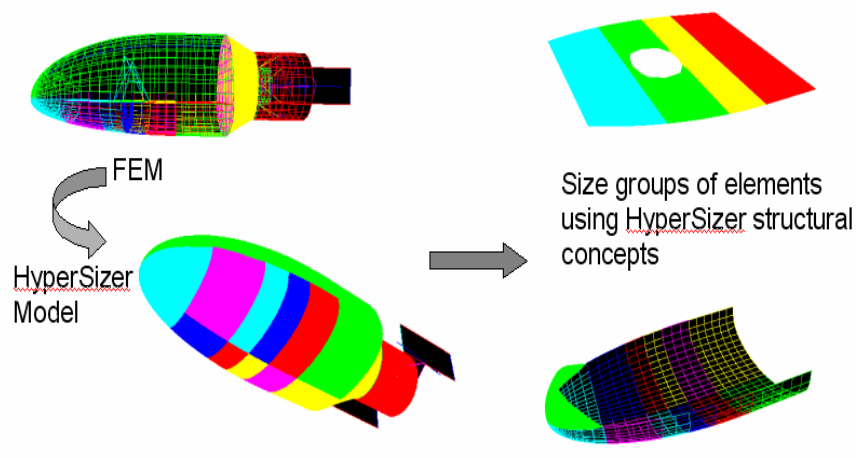

Figure 7. HyperSizerTM Analysis Path

$\mathrm{A} F / \mathrm{B}$ and $\mathrm{B} / \mathrm{S}$ were created and attached together at locations where they would separate after aerocapture. Groups of finite elements were created for optimizing in HyperSizer ${ }^{\mathrm{TM}}$ and are shown as different colors in Figs. 46. Stiffening of the payload deck and aeroshell became necessary as the analysis proceeded. Figure 6 shows a major bulkhead required to support the Hydrazine tank and axial stiffeners to help transfer loads during launch. TPS mass was input into HyperSizerTM as NSM and could easily be altered to suit different thermal material trade studies. Launch and aerocapture loading and structure stiffness requirements from Table 1 in the Design Loads section were used. An older cruise stage FEM from a previous design study ${ }^{13}$ was used to obtain estimated full stack stiffness to check launch-configuration natural frequencies. Subsystem/payload component masses from the latest MEL were lumped on the stiffened payload deck based on the latest design. Components were constantly being moved during the design, causing many modifications to the analysis. Later in the study the HGA antenna was replaced with a deployable antenna. This decision drastically affected the aeroshell design since the maximum geometry to fit the rigid HGA was no longer required. The aeroshell volume could be shrunk to minimize structural mass. This led to a final design concept requiring a $2.88 \mathrm{~m}$ long ellipsled that also represented the most current MEL. The design study was then divided into two paths: one using a $5.5 \mathrm{~m}$ long ellipsled and the other using a $2.88 \mathrm{~m}$ ellipsled that also represented the most current design and MEL. The purpose for having two design concepts was to provide maximum and minimum structural mass estimates for the systems study. The $5.5 \mathrm{~m}$ ellipsled design was finished to give mission planners a maximum structural mass and internal volume if a larger ellipsled is required. 


\section{5.5m Ellipsled Structural Analysis Results}

The final structural member masses for the $5.5 \mathrm{~m}$ ellipsled are shown in Table 3 below $^{15}$, followed by more detailed construction descriptions. These results were considered worst case structural mass estimates for the given aerocapture mission to Neptune.

Table 3. 5.5m Ellipsled Component Masses

\begin{tabular}{|lcll|}
\hline \multicolumn{1}{|c}{ Component } & \multicolumn{1}{c|}{$\begin{array}{c}\text { Area } \\
\left(\mathbf{m}^{2}\right)\end{array}$} & $\begin{array}{l}\text { Structural } \\
\text { Mass }(\mathrm{kg})\end{array}$ & \multicolumn{1}{c|}{$\begin{array}{c}\text { TPS Mass } \\
(\mathbf{k g})\end{array}$} \\
Heatshield (F/B) & $\mathbf{2 2 . 4 7}$ & $\mathbf{2 1 0 . 5 4}$ & $\mathbf{1 2 4 5 . 3 5}$ \\
B/S & $\mathbf{2 1 . 3 0}$ & $\mathbf{1 5 1 . 5 7}$ & $\mathbf{1 1 8 . 0 2}$ \\
Payload Deck & $\mathbf{1 2 . 8 8}$ & $\mathbf{2 7 1 . 4 8}$ & No TPS \\
Aft Bulkhead & $\mathbf{6 . 3 7}$ & $\mathbf{4 0 . 3 6}$ & $\mathbf{3 5 . 2 8}$ \\
Totals & & 673.95 & $\mathbf{1 3 9 8 . 6 5}$ \\
\hline
\end{tabular}

Heatshield (F/B) $-5.08 \mathrm{~cm}$ thick with a Hexcell 5052 Alloy Hexagonal Al Honeycomb core and $16.51 \mathrm{~mm}$ GrPolyimide face sheets

B/S- $3.39 \mathrm{~cm}$ thick with a Hexcell 5052 Alloy Hexagonal Al Honeycomb core and $16.51 \mathrm{~mm}$ Gr-Polyimide face sheets

Aft Bulkhead - $2.54 \mathrm{~cm}$ thick with a Hexcell 5052 Alloy Hexagonal Al Honeycomb core and $16.51 \mathrm{~mm}$ Gr Polyimide face sheets

Payload Deck -Al Isogrid

The two lowest lateral stack modes were $17.51 \mathrm{~Hz}$ and $17.93 \mathrm{~Hz}$. The lowest axial mode was $49.98 \mathrm{~Hz}$, involving structure for the orbiter thrusters. All local buckling checks were performed within HyperSizer ${ }^{\mathrm{TM}}$.

Honeycomb core with facesheets was used for the overall aeroshell design. It provided the lowest mass that met all stress and dynamic modes criteria for the aeroshell. The isogird design shown in Fig. 8 was selected for the scientific payload platform. The detailed geometry would have been difficult and time consuming to create with a typical FEA. HyperSizer ${ }^{\text {TM }}$ was able to quickly show a payload deck isogrid design that is well suited for mounting components with ample openings for running cables and piping. The isogird design mass was roughly the same as that required for a blade stiffened payload deck using honeycomb.

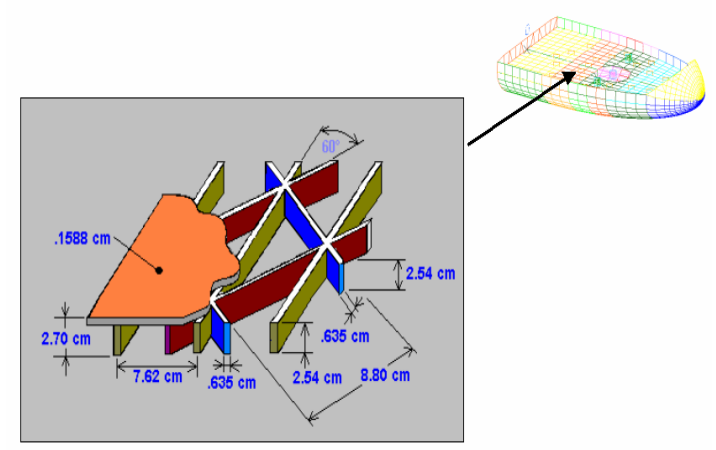

Figure 8. Payload Deck Isogrid Design

As mentioned above, preliminary mass estimates and HGA design changes allowed the ellipsled to be reduced to $2.88 \mathrm{~m}$. Figure 9 shows a size/design comparison between the original, larger $5.5 \mathrm{~m}$ aeroshell with old cruise stage, and the revised, smaller $2.88 \mathrm{~m}$ ellipsled with new cruise stage, described more fully in the next sections. 


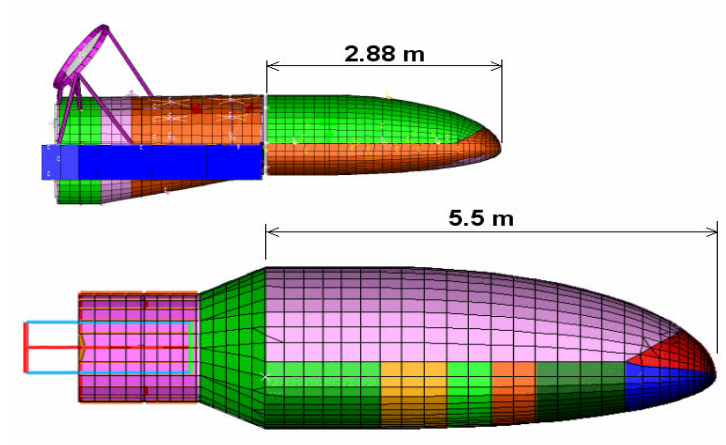

Figure 9. 5.5m and 2.88m Ellipsled Comparison

\section{2.88m Ellipsled Design}

After initial structure and TPS mass estimates showed unacceptably high values for the $5.5 \mathrm{~m}$ ellipsled, and changes were made to use a deployable HGA, a parallel analysis effort was started to size a smaller ellipsled. The ellipsled was reduced to $3.5 \mathrm{~m}$, then $3.2 \mathrm{~m}$, then finally $2.88 \mathrm{~m}$. Figures $10^{16}$ and 11 show the full stackup design and its FEM, respectively, for the $2.88 \mathrm{~m}$ ellipsled in the Delta IV Heavy $5 \mathrm{~m}$ fairing. Figures $12^{16}$ and 13 show the ellipsled orbiter design, with major functional components, and its FEM, respectively.

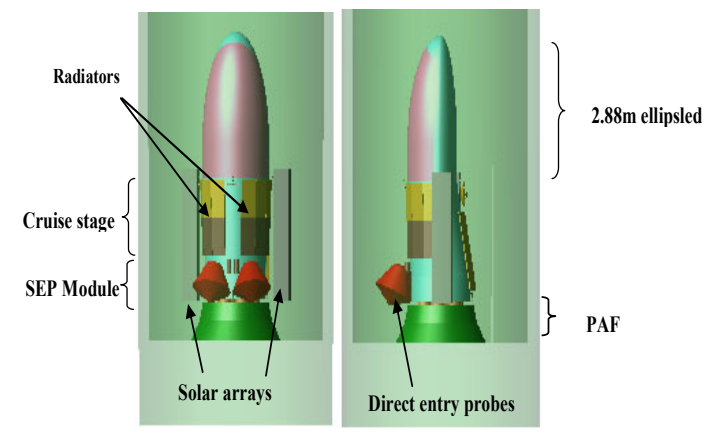

Figure 10. Full Stackup with $2.88 \mathrm{~m}$ Ellipsled in 5m Delta IV Heavy Fairing

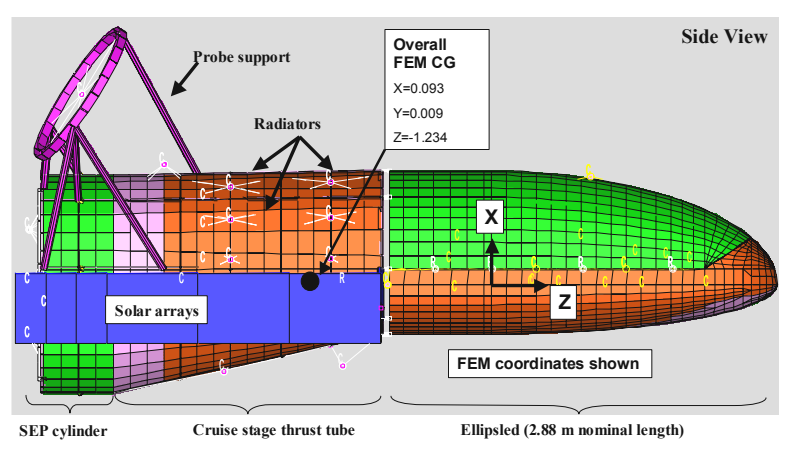

Figure 11. Full Stackup FEM

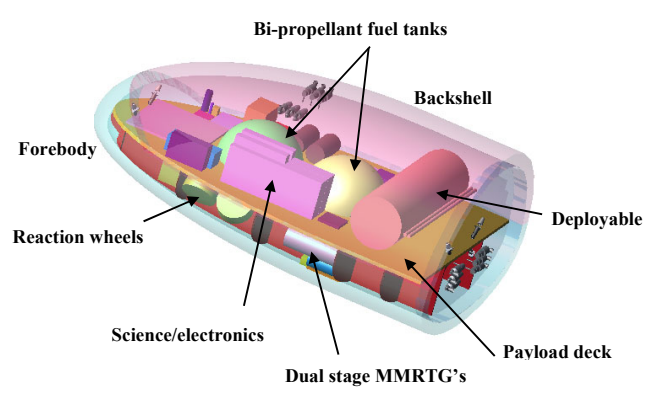

Figure 12. 2.88m Ellipsled Orbiter

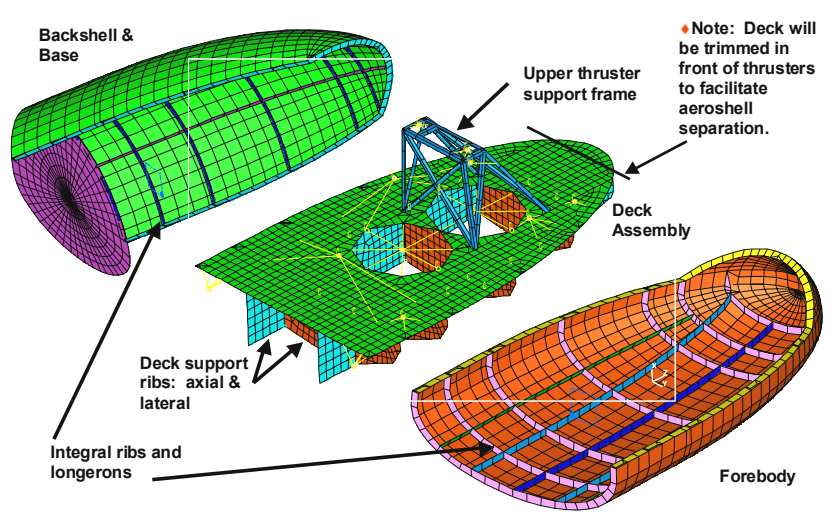

Figure 13. 2.88m Ellipsled Orbiter FEM 
The F/B and B/S base are uniform $2.54 \mathrm{~cm}$ thick sandwich structure with $5052 \mathrm{Al}$ honeycomb and $0.132 \mathrm{~cm} \mathrm{Gr}$ Polyimide facesheets, stiffened with $0.318 \mathrm{~cm}$ thick integral monolithic composite blade longerons and circumferential ribs. The payload deck is also a $2.54 \mathrm{~cm}$ thick sandwich structure with $5052 \mathrm{Al}$ honeycomb and $0.132 \mathrm{~cm}$ Gr-Polyimide facesheets. It is stiffened with full-depth lateral and longitudinal sandwich structure ribs, $1.27 \mathrm{~cm}$ thick with $5052 \mathrm{Al}$ honeycomb and $0.132 \mathrm{~cm}$ Gr-Polyimide facesheets. The bi-propellant fuel tanks are further supported by small Al tube struts under the deck. The upper frame is $2.54 \mathrm{~cm} \times 2.54 \mathrm{~cm} \times 0.130 \mathrm{~cm} \mathrm{Al}$ angles, and supports thrusters for on-orbit attitude control. The ellipsled is tied to the PM/cruise stage with eight pyrotechnic fittings which separate the ellipsled from the cruise stage prior to aerocapture. The payload deck is tied to the $\mathrm{F} / \mathrm{B}$ and $\mathrm{B} / \mathrm{S}$ base with twenty separation fittings which fire after aerocapture to separate the $\mathrm{F} / \mathrm{B}$ and $\mathrm{B} / \mathrm{S}$, leaving the payload deck on orbit. During aerocapture, the component inertia loads from the orbiter's high-g deceleration are transmitted across the payload deck panels, into the ribs, then into the aeroshell (primarily the F/B), where they are balanced by the aeropressure loads on the aeroshell exterior.

Figures $14^{16}$ and 15 show the PM/cruise stage design with functional components, and its FEM representation with major structural components, respectively. Both the SEP cylinder and cruise stage thrust tube are stiffened skin construction. The $0.254 \mathrm{~cm} \mathrm{Al} \mathrm{skin} \mathrm{is} \mathrm{stiffened} \mathrm{by} \mathrm{a} \mathrm{series} \mathrm{of} \mathrm{Al} \mathrm{longerons} \mathrm{and} \mathrm{rings,} \mathrm{as} \mathrm{shown} \mathrm{in} \mathrm{Fig.} \mathrm{16,} \mathrm{which}$ transmit launch loads into the PAF and provide hard points for component attachments such as the hydrazine and Xe tanks, SA's, radiators, etc. An Al ring frame at the bottom of the SEP cylinder, stiffened by $5.08 \mathrm{~cm} \mathrm{Al}$ tube struts, provides attach points for the six SEP engines. The two entry probes are supported by $5.08 \mathrm{~cm} \mathrm{Al}$ channel-section rings with $5.08 \mathrm{~cm} \mathrm{Al}$ tube trusses. The Xe tank is supported by a $5.08 \mathrm{~cm} \mathrm{Al} \mathrm{channel-section} \mathrm{ring} \mathrm{and} 5.08 \mathrm{~cm} \mathrm{Al}$ tube struts at the bottom, and $2.54 \mathrm{~cm} \mathrm{Al}$ tube struts at the top. The hydrazine tank is supported by a single $\mathrm{Al}$ ring with stiffening struts. During launch, the ellipsled inertia loads enter the PM/cruise stage via the eight separation fittings. The inertia loads from the individual PM/cruise stage components enter the stiffened skin structure through their respective support structure. All of these loads are then transmitted down the stiffened skin, eventually being reacted at the PAF.

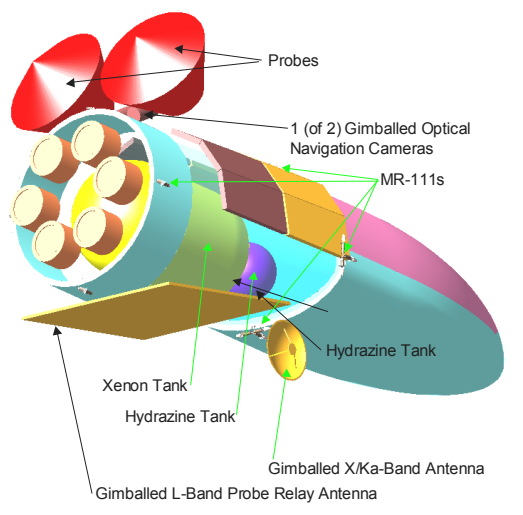

Figure 14. PM/Cruise Stage Components

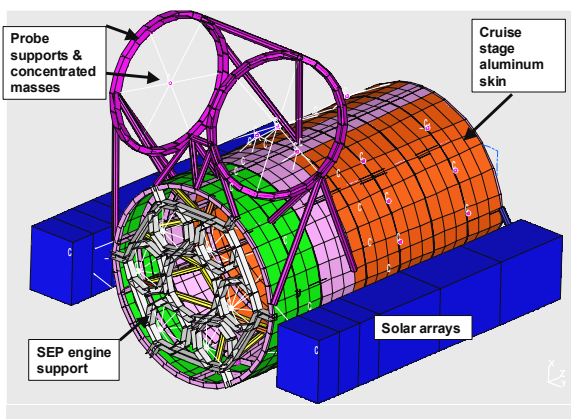

Figure 15. PM/Cruise Stage FEM

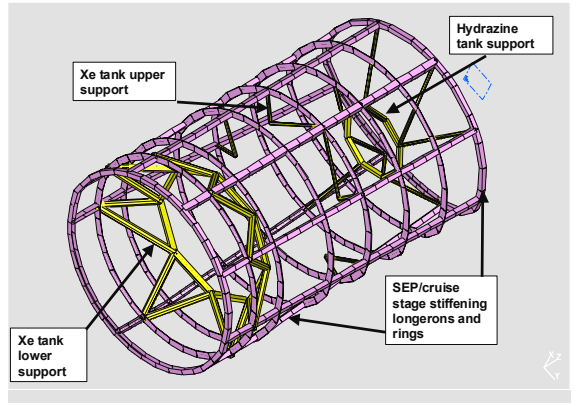

Figure 16. PM/Cruise Stage FEM showing internal longerons and rings 


\section{E. 2.88m Ellipsled Structural Analysis Results}

The FEM modal analysis showed that both the ellipsled and PM/cruise stage structures were largely stiffness critical, and were thus primarily sized to maintain the minimum design natural frequencies during launch. The full depth ribs on the ellipsled payload deck and their attachment to the aeroshell F/B kept the local deck natural frequency above $32 \mathrm{~Hz}$. The minimum natural frequencies for the full stackup at launch were $11.08 \mathrm{~Hz}$ lateral and $32.01 \mathrm{~Hz}$ axial, above the 8 and $30 \mathrm{~Hz}$ requirements ${ }^{2}$, respectively. The lateral mode involved the full stack bending in the "weakwise" direction, normal to the payload deck, while the axial mode involved the SEP engines and their support structure "bouncing" in the direction of the stackup longitudinal axis.

Since the structure was largely stiffness critical, the FEM static analyses showed generally high structural margins of safety, with only a few local high stress areas. On the ellipsled, the areas of lowest MS were the F/B longeron strength at the $\mathrm{B} / \mathrm{S}$ separation fitting interface during aerocapture, and the propellant tank support strut buckling at aerocapture. On the PM/cruise stage, the lowest MS was against bending of the SA base support during launch. The maximum static deflection of $0.66 \mathrm{~cm}$ occurred at the ellipsled nose during launch for the maximum lateral $\mathrm{g}$ condition. An I-DEAS eigenvalue buckling solution of the full stackup showed a buckling margin of safety of 2.47, with the critical location being the upper Al skin panel on the cruise stage.

Summaries of the ellipsled alone and full stackup masses are shown in Tables 4 and 5 below. Table 4 shows the ellipsled alone evaluated for aerocapture loading. The total mass of $1412 \mathrm{~kg}$ includes $474.2 \mathrm{~kg}$ of TPS mass and $136.5 \mathrm{~kg}$ of CBE structure mass.

Table 4. Ellipsled Only Mass Summary: Aerocapture Evalutaion

\begin{tabular}{|l|l|}
\hline Item & Mass (kg) \\
\hline Forebody & 464.4 \\
\hline F/B TPS (growth) & 419.5 \\
\hline F/B structure & 44.9 \\
\hline \hline Backshell & $\mathbf{8 4 . 9}$ \\
\hline B/S TPS (growth) & 42.1 \\
\hline B/S structure & $\mathbf{4 2 . 8}$ \\
\hline \hline Base & 19.75 \\
\hline Base TPS (growth) & 12.6 \\
\hline Base structure & $\mathbf{7 . 1 5}$ \\
\hline \hline Deck & 191.6 \\
\hline Deck NSM (growth) & $\mathbf{1 7 0}$ \\
\hline Deck structure & $\mathbf{2 1 . 6}$ \\
\hline \hline Deck ribs structure & 17.9 \\
\hline \hline Lumped masses (growth) & $\mathbf{6 3 1 . 2}$ \\
\hline Tanks, etc. & 606.5 \\
\hline Separation fittings & $\mathbf{2 4 . 7}$ \\
\hline \hline Tank support rods & $\mathbf{0 . 4 2}$ \\
\hline \hline Thruster support frame & 1.75 \\
\hline \hline Total TPS Mass (growth) & $\mathbf{4 7 4 . 2}$ \\
\hline \hline Total Structure Mass (CBE) & $\mathbf{1 3 6 . 5}$ \\
\hline \hline Total Ellipsled Mass & $\mathbf{1 4 1 2}$ \\
\hline \hline
\end{tabular}

In Table 5, the total stackup mass of $4190.4 \mathrm{~kg}$ includes $1460.4 \mathrm{~kg}$ for the ellipsled (which includes the $30 \%$ growth factor applied to the CBE structure mass from above) and $2730 \mathrm{~kg}$ for the $\mathrm{PM} /$ cruise stage. The PM/cruise stage mass includes $203.82 \mathrm{~kg}$ of CBE structure mass. For the full system analysis mass tracking, the CBE values are increased by $30 \%$ for growth values, giving a total structure mass for the stackup at launch of $442.4 \mathrm{~kg}$. 
Table 5. Full Stackup Mass Summary at Launch

\begin{tabular}{|c|c|c|c|}
\hline \multicolumn{3}{|l|}{ Components } & \multirow{2}{*}{$\begin{array}{l}\text { Mass (kg) } \\
1460.4\end{array}$} \\
\hline Ellipsled Total & & & \\
\hline \multirow[t]{10}{*}{ Aeroshell total } & & & 597.81 \\
\hline & Forebody total & & 478.1 \\
\hline & & F/B TPS & 419.5 \\
\hline & & $\begin{array}{l}\text { F/B } \\
\text { structure }\end{array}$ & 58.6 \\
\hline & Backshell total & & 97.81 \\
\hline & & B/S TPS & 42.12 \\
\hline & & $\begin{array}{l}\mathrm{B} / \mathrm{S} \\
\text { structure }\end{array}$ & 55.69 \\
\hline & Base total & & 21.9 \\
\hline & & Base TPS & 12.61 \\
\hline & & $\begin{array}{l}\text { Base } \\
\text { structure }\end{array}$ & 9.29 \\
\hline \multirow[t]{8}{*}{ Payload total } & & & 803 \\
\hline & Deck total & & 198.1 \\
\hline & & Deck NSM & 170 \\
\hline & & $\begin{array}{l}\text { Deck } \\
\text { structure }\end{array}$ & 28.1 \\
\hline & $\begin{array}{c}\text { Deck rib } \\
\text { structure }\end{array}$ & & 23.29 \\
\hline & Thruster support & & 1.75 \\
\hline & $\begin{array}{c}\begin{array}{c}\text { Tank support } \\
\text { rods }\end{array} \\
\end{array}$ & & 0.42 \\
\hline & Lumped masses & & 606.5 \\
\hline Separation fittings & & & 32.11 \\
\hline \multirow[t]{14}{*}{ Cruise stage total } & & & 2730 \\
\hline & $\begin{array}{c}\text { SEP cylinder } \\
\text { total }\end{array}$ & & 144.6 \\
\hline & & NSM & 114.82 \\
\hline & & Structure & 29.78 \\
\hline & Thrust tube total & & 168.2 \\
\hline & & NSM & 78.32 \\
\hline & & Structure & 89.89 \\
\hline & Probe support & & 31.32 \\
\hline & $\begin{array}{l}\text { Hydrazine tank } \\
\text { support }\end{array}$ & & 3.4 \\
\hline & $\begin{array}{c}\text { SEP Engine } \\
\text { support }\end{array}$ & & 30.28 \\
\hline & $\begin{array}{c}\text { Solar array } \\
\text { support }\end{array}$ & & 3.54 \\
\hline & Solar arrays & & 400.4 \\
\hline & XE tank support & & 15.61 \\
\hline & Lumped masses & & 1932 \\
\hline Total stackup & & & 4190.4 \\
\hline
\end{tabular}




\section{Post-Study Evaluation with HypersizerTM}

Due to the numerous iterations involved in integrating the required system/payload components and associated support structure into the available volume allowed by the $2.88 \mathrm{~m}$ flattened ellipsled shape, structural mass optimization was not performed within the original design schedule. Shortly after the systems review for the Neptune Aerocapture study (October 28, 29, 2003), further analysis was performed on the $2.88 \mathrm{~m}$ ellipsled using HyperSizer ${ }^{\mathrm{TM}}$ in an effort to realize some gains by optimizing the ellipsled structure mass. As discussed earlier, HyperSizer $^{\mathrm{TM}}$ reads in the FEM mesh and internal loads from an outside FEA (in this case I-DEAS), then steps through a user-defined design space, applying the internal loads to local model regions called panels. While not a true optimizer, HyperSizer ${ }^{\mathrm{TM}}$ uses closed form solutions to step through all user-specified material, size, and construction method permutations for each model panel to find the lightest structure to pass all strength and stability requirements. This can result in adjacent panels having totally different sizing or construction techniques. While the result may yield the lightest possible structure, it is often not a manufacturable one. The user may then need to adjust the design space or link certain panels for the sake of manufacturability and rerun HyperSizer ${ }^{\mathrm{TM}}$. Lastly, since HyperSizer ${ }^{\mathrm{TM}}$ only checks local panel buckling modes and natural frequencies, the full FEM must be reevaluated in the FEA code for global stability and natural frequencies.

For the mass optimization on the ellipsled structure, only the sandwich construction family of panels was looked at. This was primarily due to previous experience with this type of structure ${ }^{15}$ and due to time limitations. As a result of the HyperSizer ${ }^{\mathrm{TM}}$ analysis, the ellipsled structure mass was reduced by $39.1 \mathrm{~kg}$, from $134.4 \mathrm{~kg}$ (the upper thruster frame and propulsion tank supports were not evaluated) to $95.3 \mathrm{~kg}$. The first pass through HyperSizer ${ }^{\mathrm{TM}}$ showed a $56.2 \mathrm{~kg}$ mass reduction, but all of this could not be realized when adjustments were made for structure manufacturability. The resulting structure was re-evaluated in I-DEAS to check global stability and natural frequencies. As a result of reducing mass without significant stiffness reduction, the overall stackup natural frequency climbed slightly from $11.08 \mathrm{~Hz}$ to $11.84 \mathrm{~Hz}$. For the ellipsled only at aerocapture, the global buckling margin of safety increased from 1.97 to 2.51 . For the full stackup, the global buckling margin increased from 2.47 to 3.15 .

\section{Conclusions}

A successful aerocapture mission at Neptune depends on success of many subsystems, including structure that will house and support the required payload, sustain launch loads, sustain aerocapture inertia loads and heating, and provide all of the above with a minimum mass. The structural analysis portion of the Neptune aerocapture systems design study showed that the chosen stackup design of a stiffened-skin construction PM/cruise stage supporting a $2.88 \mathrm{~m}$ ellipsled aerocapture vehicle is a feasible approach when using a Delta IV Heavy launch vehicle, and that the stiffened sandwich ellipsled structure design is a feasible approach for aerocapture at Neptune. The resulting structure masses were within system allocations and allowed a total spacecraft mass that would meet the mission requirements. The results of this study may serve as a starting point for more refined analyses of a Neptune aerocapture ellipsled and cruise stage. In addition, several observations were made from the study results:

1. The flattened ellipsled shape was volumetrically inefficient in that CG requirements pushed components towards the bottom of the ellipsled, leaving the upper portion largely unused.

2. The MEL was under constant revision and was not connected to a 3D model that could be imported into IDEAS. Analysis and MEL should be completely integrated to allow the analysts the most updated design information.

3. The aeroshell sizing and payload support structure sizing were strongly linked, and required numerous separation fittings to provide load paths from the payload deck to the aeroshell. Further analysis and optimization is warranted to help reduce this separation system complexity.

4. The use of HyperSizer ${ }^{\mathrm{TM}}$ sizing software in this study demonstrated its capabilities to the design study team and displayed how it may be applied to ellipsled geometry. The software greatly reduced analysis time by using the same finite element mesh for many trial configurations. Typical FEA modeling of bladed stiffened panels would have the analysts modeling separate stiffeners and requiring a remesh after each solution of the model. HyperSizer ${ }^{\mathrm{TM}}$ avoids this and allows many trial iterations in one solution. Further mass reduction may be possible by applying HyperSizer ${ }^{\mathrm{TM}}$ to the cruise stage structure.

\section{Acknowledgements}

The author wishes to acknowledge the following people for their contributions to the Neptune aerocapture system structural analysis: Nora Okong'o and Rob Bailey (JPL) for their work in packaging the ellipsled and cruise 
stage payloads within the constraints of the structural layout; Bernie Laub (ARC) for the TPS sizing on the ellipsled forebody and backshell; and Glenn Hrinda (LaRC) for the initial structural sizing on the $5.5 \mathrm{~m}$ aeroshell and for guidance in using HyperSizerTM.

\section{References}

${ }^{1}$ Lockwood, M.K., “Overview”, Neptune Aerocapture Systems Analysis Review, Marshall Space Flight Center, Huntsville, AL, October 28, 29, 2003.

2"'Delta IV Payload Planners Guide", The Boeing Company, Huntington Beach, CA, 2000.

${ }^{3}$ Starr, B.R., and Powell, R.W., "Simulation, Monte Carlo, Performance", Neptune Aerocapture Systems Analysis Review, Marshall Space Flight Center, Huntsville, AL, October 28, 29, 2003.

${ }^{4}$ EDS PLM Solutions I-DEAS software versions 9 and higher, Electronic Data Systems Corporation, Plano, TX.

${ }^{5}$ Collier Research Corporation, HyperSizer ${ }^{\mathrm{TM}}$ Structural Sizing Software, Book 1: Tutorial \& Applications, Second Edition, Collier Research Corporation, October 1998.

${ }^{6}$ Justus, C.G., Duvall, A., and Keller, V., "Atmosphere”, Neptune Aerocapture Systems Analysis Review, Marshall Space Flight Center, Huntsville, AL, October 28, 29, 2003.

${ }^{7}$ Noca, M., "Mission Analysis", Neptune Aerocapture Systems Analysis Review, Marshall Space Flight Center, Huntsville, AL, October 28, 29, 2003.

${ }^{8}$ Edquist, K.T., "Configuration \& Aerodynamics", Neptune Aerocapture Systems Analysis Review, Marshall Space Flight Center, Huntsville, AL, October 28, 29, 2003.

${ }^{9}$ Laub, B., and Chen, Y.K., "Preliminary TPS Sizing for Neptune Aerocapture", Powerpoint Presentation, April 10, 2003.

${ }^{10}$ Hollis, B.R., and Olejniczak, J., "Aeroheating Environments", Neptune Aerocapture Systems Analysis Review, Marshall Space Flight Center, Huntsville, AL, October 28, 29, 2003.

${ }^{11}$ Hoffman, D., and Rea, J., "Aerodynamic Stability Analysis", Neptune Aerocapture Systems Analysis Review, Marshall Space Flight Center, Huntsville, AL, October 28, 29, 2003.

${ }^{12}$ Laub, B., and Chen, Y.K., "Thermal Protection (TPS)", Neptune Aerocapture Systems Analysis Review, Marshall Space Flight Center, Huntsville, AL, October 28, 29, 2003.

${ }^{13}$ Lam, J., "Spacecraft Structure", Titan Aerocapture Systems Analysis Review, Jet Propulsion Laboratory, Pasadena, CA, August 29, 30, 2002.

${ }^{14}$ MSC/NASTRAN Quick Reference Guide, The MacNeal-Schwendler Corporation, 1992.

${ }^{15}$ Hrinda, G.A., "Structure for the 5.5 m Ellipsled", Neptune Aerocapture Systems Analysis Review, Marshall Space Flight Center, Huntsville, AL, October 28, 29, 2003.

${ }^{16}$ Bailey, R.W., Okong'o, N., Spilker, T., and Dyke, R.E., "Spacecraft Configuration", Neptune Aerocapture Systems Analysis Review, Marshall Space Flight Center, Huntsville, AL, October 28, 29, 2003. 